\title{
Verdad, carne y salvación \\ Consideraciones a propósito del enigma teológico de la verdad bíblica
}

\author{
Álvaro Pereira Delgado \\ Centro de Estudios Teológicos de Sevilla
}

\begin{abstract}
Resumen: ¿Es verdad todo lo que dice la Biblia? ¿En qué sentido la Biblia es verdad? Tras los cuestionamientos de la arqueología, la biología, la filología y demás ciencias, el lector creyente de hoy se pregunta si puede seguir leyendo la Biblia como Sagrada Escritura por la que Dios comunica su verdad. El presente artículo pretende ser una meditación teológica sobre el enigma de la verdad bíblica relacionándola con tres categorías correlativas: historia, encarnación y salvación. Nos preguntaremos, además, sobre por qué Dios ha escogido para revelarse este discreto "estilo divino", al decir de Benedicto XVI.
\end{abstract}

\begin{abstract}
Is it true everything that is contained in the Bible? In what sense is the Bible real? After many questionings from archeology, biology, philology and other sciences, a current believer lector is wondering whether he/she may keep reading the Bible as a Sacred Writing through which God communicates His truth. This paper pretends to be a theological meditation about the mystery of the biblical truth by means of three correlated categories: history, incarnation and salvation. We also wonder why God has chosen for his revelation this gentle"divine style", following Pope Benedict XVI.
\end{abstract}

«Los libros santos del Antiguo Testamento son todos palabra de Dios, parte sustancial de su revelación. Conforme al desarrollo gradual de la revelación, en ellos aparece el crepúsculo del tiempo que debía preparar el pleno mediodía de la Redención. En algunas partes se habla de la imperfección humana, de su debilidad y del pecado, como no puede suceder de otro modo cuando se trata de libros de historia y legislación. [...] Pero cualquiera que no esté cegado por el prejuicio o por la pasión no puede menos de notar que lo que más luminosamente resplandece, a pesar de la debilidad humana de que habla la historia bíblica, es la luz divina del camino de la salvación, que triunfa al fin sobre todas las debilidades y pecados. Y precisamente sobre este fondo, con frecuencia sombrío, la pedagogía de la salvación eterna se ensancha en perspectivas, las cuales a un tiempo dirigen, amonestan, 
sacuden, consuelan y hacen felices. Sólo la ceguera y el orgullo pueden hacer cerrar los ojos ante los tesoros de saludables enseñanzas encerrados en el Antiguo Testamento. Por eso, el que pretende desterrar de la Iglesia y de la escuela la historia bíblica y las sabias enseñanzas del Antiguo Testamento, blasfema la palabra de Dios, blasfema el plan de la salvación dispuesto por el Omnipotente y erige en juez de los planes divinos un angosto y mezquino pensar humano» (Pío XII, Mit brenneder Sorge 19) ${ }^{1}$.

Tras las bambalinas del discurso teológico aparentemente teórico de estas palabras, latía el palpito profundamente encarnado de la defensa de la dignidad de la persona. Con ellas, Pío xII intentaba en 1937 oponerse a la ideología nazi que, entre otras muchas opciones antisemitas, despreciaba la verdad del Antiguo Testamento.

Desde otras posturas y con otros presupuestos, los lectores actuales -también los creyentes- siguen preguntándose hoy: ¿por qué Dios comunicó sus palabras a través de los escritos de hombres limitados cuyas expresiones marcadas por su tiempo y carácter parecen «oscurecer» la claridad y excelencia de la supuesta verdad divina? ¿No pudo escoger Dios vías menos ambiguas? En este ensayo -que no es propiamente un artículo de investigación, sino más bien una meditación teológica acerca del enigma de la verdad bíblica-, vamos a intentar reflexionar sobre dicha pregunta.

Desde que la ciencia moderna cuestionó ciertos asertos bíblicos acogidos anteriormente como certezas incontrovertibles, la apologética cristiana ha intentado fatigosamente responder al siguiente enigma: si Dios se comunica a través de los textos bíblicos y todo lo que proviene de Dios debe ser verdad, ¿cómo se explica que la Biblia contenga afirmaciones dudosas? ¿cómo es posible que, según el ConcilioVaticano II, Dios diga en sus Sagradas Escrituras «cosas imperfectas» (Dei Verbum 14)?

Siendo un muchacho de dieciocho años, escuché con pasión el planteamiento de este enigma por el Profesor Gonzalo Flor Serrano, buen maestro y magnífico compañero del Departamento de Sagrada Escritura. Sirvan estas sencillas consideraciones de sentido homenaje al magisterio de Gonzalo. Relacionaré la verdad bíblica con la historia, con la encarnación y con la salvación, sin pretender con ello una propuesta sistemática.

\section{VERDAD E HISTORIA}

Tras muchos siglos de creencia en que la Biblia era inerrante en todos los ámbitos (ciencias naturales, historia, moral, etc.), los avances en astronomía en el siglo XVII pusieron en duda ciertas afirmaciones bíblicas. Recuérdese, por ejemplo, el caso Galileo y la condena de la traslación de la tierra en torno al sol a partir de

<https://w2.vatican.va/content/pius-xi/es/encyclicals/documents/hf_p-xi_enc_14031937_mitbrennender-sorge.html> (acceso 1-11-2017). 
Josué 10,12-14². Galileo, siempre interesante, replicó a sus críticos con una frase antológica: «La intención del Espíritu Santo es enseñarnos cómo se va al cielo, y no cómo va el cielo» ${ }^{3}$. En el siglo xIx, se sumó la hostilidad de los resultados científicos de la teoría de la evolución yde la crítica histórica. Los hallazgos de las ciencias naturales, la arqueología y los estudios de las lenguas orientales fueron cuestionando numerosos asertos veterotestamentarios. La apologética cristiana respondió con respuestas concordistas que no convencieron a nadie. De hecho, en la actualidad, multitud decontenidos bíblicos en materia de biología, cronología o moral aparecen como imperfectos, desfasados, o simplemente erróneos. No sería honestohoy rehuir la evidencia de estas demostracionescientíficas por temor a que se derrumbe nuestra fe en la verdad de la Sagrada Escritura. La salida concordista o la cerrazón fundamentalista no sonya respuestas razonables ${ }^{4}$. Si, a pesar de todo, estos enunciados bíblicos deben ser considerados como verdad merced a su autoría divina, ¿en qué sentido pueden ser tenidos como verdad?

No obstante, también es necesario afirmar que dichasevidencias no destruyenla base histórica general de unos escritos que nacieron en un tiempo y espacio determinado como resultado de unas vivencias históricas específicas. Así, por ejemplo, aunque los estudiosos hoy consideren el relato de Jonás una divertida e inteligente novela de ficción, quizás basada en el remoto recuerdo de un profeta llamado Jonás (cf. 2 Reyes 14,25), no cabe duda de que dicho escrito nació en un contexto histórico -el judaísmo post-exílico- al servicio de unos intereses teológicos que pretendían influir en su realidad histórica -la crítica ante un exclusivismo judío que olvidaba la misericordia divina $-^{5}$.

Más aún, independientemente de la veracidad histórica de este o aquel relato, de esta o aquella afirmación, los pasajes bíblicos son el producto de la memoria colectiva de un pueblo que escribió y reescribió constantemente su historia a la luz de su fe.La convicción fundamental de dicha fe estribaba en que Dios era aquel que los había librado de la esclavitud de Egipto, de las asechanzas de Asiria y del destierro de Babilonia. Ellos jamás dudaron de que Dios había intervenido en la historia para cambiar su signo, por mucho que los especialistas en arqueología e

2 Cf. Ernan McMuluin, «Galileo's Theological Venture», Zygon48 (2013) 192-220; y George V. Coyne, SJ, «Science Meets Biblical Exegesis in the Galileo Affair», Zygon48 (2013) 221-229.

3 Carta a la Gran Duquesa de la Toscana (1615); cita tomada de Antonio M. Artola - José Manuel Sánchez Caro, Biblia y Palabra de Dios (Introducción al estudio de la Biblia 2; Estella, Verbo Divino, 1995) 225, nota 18.

4 Verbum Domini 44: «El fundamentalismo [...] tiende a tratar el texto bíblico como si hubiera sido dictado palabra por palabra, y no llega a reconocer que la Palabra de Dios ha sido formulada en un lenguaje y en una fraseología condicionadas por una u otra época determinada».

5 «En el caso de Tobías y Jonás, se percibe que estos textos no relatan hechos realmente ocurridos y que, pese a ello, se trata de relatos llenos de significado edificante, didáctico y teológico»: PONTIFICIA COMIIIÓN Bíblica, Inspiración y verdad de la Sagrada Escritura. La Palabra que viene de Dios y habla de Dios para salvar al mundo (BAC-documentos; Madrid, Bac, 2014), § 135, pags. 241-242. Para conocer mejor el contexto histórico y la significación teológica del libro de Jonás, cf. Erich Zenger (ed.), Introduzione all'Antico Testamento (Brescia, Queriniana, 2005) 827-835. 
historia afirmen que no existen evidencias para probar la certeza científica de estos hechos que, por su naturaleza teologal, se escapan a la comprobación empírica.

Es preciso esclarecer, en este sentido, que el estatuto epistemológico de esta convicción no se basa en una demostración científica -siempre perfectible, dicho sea de paso, por el mismo carácter provisorio del método histórico-crítico-, sino en el testimonio personal de una cadena ininterrumpida de testigos. La convicción de que Dios ha actuado en la historia y la ha atravesado de parte a parte en la encarnación, muerte y resurrección de su Hijo puede ser estudiada y confirmada por la ciencia exegética; pero, en última instancia, el fundamento de su verdad radica en la credibilidad de los testigos. Ellos son los que reconocen en dicha historia una nueva dimensión de misterio que la hace historia de salvación. Así pues, la base de la revelación bíblica no estriba en una gnosis científica, sino en el testimonio personal de nuestros mayores. Como decía el teólogo von Balthasar, «solo el amor es digno de fe». En este sentido, deberíamos evitar la tentación de considerar la Biblia como propiedad de los científicos, hurtándosela al pueblo de Dios. Los escritos del Antiguo Testamento nacieron de un pueblo al servicio de dicho pueblo. Asimismo, los evangelios nacieron en las comunidades cristianas para formar y confirmar a los nuevos discípulos que iban integrándose en dichas comunidades. Por tanto, el pueblo de Dios con sus pastores a la cabeza, y no los científicos, son su primer sujeto hermenéutico.

En conclusión, podemos afirmar que, aunque muchos relatos bíblicos sean ficticios o recreaciones exclusivamente literarias, la revelación bíblica no se asienta en un mito inventado, sino en la memoria colectiva de un pueblo que testimonió y transmitió por generaciones la certeza de que Dios había intervenido en la historia. Las numerosas deficiencias y contradicciones de los relatos bíblicos no invalidan esta certeza fundante.

\section{VERDAD Y ENCARNACIÓN}

Y, sin embargo, alguno seguirá dándole vueltas a la siguiente cuestión: si los creyentes leen el texto bíblico no solo como un inspirador relato humano, sino como la Palabra de la salvación inspirada por Dios, ¿cómo es posible que el Dios eterno y siempre verdadero, hable por medio de palabras imperfectas y, en algún sentido, contradictorias? Parecería que esta es una debilidad evidente de la fe judeo-cristiana que socava los cimientos mismos de su credibilidad. Sin embargo, pretendo mostrar en los siguientes párrafos que, paradójicamente, esta aparente debilidad es la verdadera fortaleza de la fe bíblica.

Algunos preferirían que Dios se hubiera revelado por medio de una «palabra descendida» ${ }^{6}$, un mensaje venido directamente del cielo. Se podría pensar que mu-

6 Tomo prestada el título del interesante libro sobre el Corán de Emilio GonZÁLEZ FERRín, La palabra descendida: un acercamiento al Corán (Premio Jovellanos de Ensayo. Oviedo, Nobel, 2002). 
chos más creerían si el Dios de los cristianos hubiera legado a los humanos principios evidentes y seguros, sin sombra de duda. ¿Por qué esta ambigüedad divina? ¿Por qué Dios ha preferido comunicarse, según la fe cristiana,por medio de unos textos que pertenecen a lenguas diversas, escritos en géneros diferentes y en tiempos distintos? ¿Por qué comunicar sus palabras santas en manuscritos polvorientos cuyos originales se han perdido y que, en ocasiones, ni los mejores científicos son capaces de descifrar? Las preguntas podrían ampliarse: ¿por qué elegir a un pueblo concreto para revelar su salvación universal? ¿por qué Israel y no Egipto? ¿por qué la necesidad de la fe, siempre entre tinieblas, y no comunicarse mejor de forma «clara y distinta»? ¿por qué la pertinencia de la mediación eclesial? O, formulado en lenguaje bíblico: «A otros ha salvado y él no se puede salvar ¡Es el Rey de Israel!, que baje ahora de la cruz y le creeremos» (Mt 27,42).Y es que, no en vano, hoy sigue siendo escandaloso que el anuncio cristiano se apoye en los quicios de la carne y de la cruz.

La respuesta a estas preguntas radica en el misterio de la encarnación ${ }^{7}$ : de la misma manera que el Hijo de Dios se ha hecho hijo del hombre, de forma que para encontrar a Dios haya que buscarlo ahí donde nadie lo buscó jamás -en un niño en pañales, en un condenado al suplicio de la cruz-; así también la Palabra de Dios se ha expresado en palabras de hombres violentos (libros de los Macabeos), descreídos (Eclesiastés), utópicos (tercer Isaías), enamorados (Cantar) o conservadores (Ageo). El Dios que no rehuyó asumir la carne, el sufrimiento y la cruz, tampoco ha evitado comunicarse a través de palabras humanas, limitadas y provisionales. Consiguientemente, el que no se escandaliza porque el Salvador haya arrostrado la ignominia de la cruz, tampoco debería escandalizarse porque Dios haya querido revelarse por medio de las palabras «imperfectas y adaptadas a sus tiempos» (Dei Verbum 14) de los autores bíblicos.Ya Pío XII afirmó explícitamente esta relación entre encarnación del Verbo y condescendencia divina:

En efecto, a la manera que el Verbo sustancial de Dios se hizo semejante a los hombres en todo menos en el pecado (cf. Heb 4,15), así también las palabras de Dios, expresadas en lenguaje humano, se hacen semejantes al lenguaje humano en todo menos en el error. Y eso es lo que ya san Juan Crisóstomo cantó magníficamente como la synkatábasis o condescendencia de Dios, afirmando que una y muchas veces se da en los libros sagrados (cf., entre otros, In Gen. 1.4; PG 53,34-35...) ${ }^{8}$.

7 La encarnación del Hijo de Dios hace posible la comunicación entre Dios y el hombre. Por ello, la encarnación es el principio fundamental de la revelación. Así afirma René Latourelle, Teología de la revelación (Verdad e Imagen 49; Salamanca, Sígueme, ${ }^{2} 1966 ;{ }^{11}$ 2005) 456: «La encarnación es la vía elegida por Dios para revelar y revelarse. Tiene por fin hacer posible en nivel humano el conocimiento de Dios y de su designio salvífico; nos fue dada para que Dios expresase al hombre en términos humanos y mediante todas las dimensiones humanas el conocimiento y amor del único verdadero. Podemos, pues, afirmar que la encarnación del Hijo, entendida concretamente, es la revelación del Hijo, y por él, del Padre».

8 Pío XII, Divino afflante Spiritu (Denzinger - Hünerman § 3830). Cita tomada de Salvador PIé-NINOT, Teología fundamental (Sapientia fidei 37; Madrid, BAC, 2016) 172. La misma idea es explicitada en la Dei Verbum 13. 
Pero esta vía desconcertante de aparente debilidad es, en realidad, la principal fortaleza del «estilo divino», en feliz expresión de Benedicto XVI'. Es la manera que Dios ha escogido para jugar limpio con el ser humano y respetar su libertad. La madurez requiere espacio. Dios se oculta para que el hombre lo busque con deseo y pueda probar el riesgo del error. Si Dios hubiera preferido ofrecer pruebas apodícticas, demostraciones a prueba de la falsación científica -aunque aquí quizás habría que escuchar, con tristeza, las palabras de Abrahán al rico: «Si no escuchan a Moisés y a los profetas, no se convencerán ni aunque resucite un muerto» (Lc 16,31)-, entonces Dios no habría dejado espacio a los hombres para una respuesta libre negativa. Como el padre que, cuando debate con su hijo adolescente, adapta sus palabras y emplea argumentos a la altura de su inteligencia para que el niño pueda entenderlo y confrontarse con él; Dios, en su infinita condescendencia, ha usado las palabras y experiencias humanas mediocres y limitadas, para poder hacer una alianza con los hombres -dicho de forma escandalosa- de igual a igual.

Este estilo discreto y débil no solo permite al hombre decirle un sí a Dios de forma libre y generosa, también evita, en segundo lugar, considerar la revelación divina como un conjunto de verdades objetivas que transmitir ${ }^{10}$. Dios no es un maestro gnóstico que quiere legarnos sus conocimientos ocultos. Él es un misterio personal que busca amistar con los seres humanos por medio de una relación de alianza. «Se puede forzar una adhesión intelectual. No se puede forzar un corazón» ${ }^{11}$. Alguno podría pensar que este estilo divino es bastante arriesgado porque deja la puerta abierta al ateísmo y a la herejía. Pero es posible que Dios tema más a un creyente que se cree en posesión completa de la verdad, que a un agnóstico que transita entre tinieblas y con honestidad los senderos del misterio. Además, que Dios haya preferido revelarse progresivamente

9 Joseph RATZINGER, Jesús de Nazaret. Desde la entrada en Jerusalén hasta su resurrección (Madrid, Encuentro, 2011) II, 321: «Es propio del misterio de Dios actuar de manera discreta. Solo poco a poco va construyendo su historia en la gran historia de la humanidad. Se hace hombre, pero de tal modo que puede ser ignorado por sus contemporáneos, por las fuerzas de renombre en la historia. Padece y muere y, como Resucitado, quiere llegar a la humanidad solamente mediante la fe de los suyos, a los que se manifiesta. No cesa de llamar con suavidad a las puertas de nuestro corazón y, si le abrimos, nos hace lentamente capaces de «ver». Pero ¿no es este acaso el estilo divino? No arrollar con el poder exterior, sino dar libertad, ofrecer y suscitar amor. Y, lo que aparentemente es tan pequeño, ¿no es tal vez -pensándolo bien- lo verdaderamente grande?».

10 La misma idea de «verdad» en la tradición judeo-cristiana es un concepto más relacional e intersubjetivo, que lógico y objetivo. La verdad para un israelita es el mantenimiento fiel a la palabra dada. Así afirma Sánchez Caro: «Mientras el griego aprehende en la contemplación filosófica lo permanente e inmutable de la naturaleza, el israelita necesita esperar en fe la realización de la promesa mesiánica o el veredicto final de la historia para conocer la verdad de las palabras de Dios... En consecuencia, la verdad israelita no está, como en la lógica griega, en la captación del sentido de los enunciados, sino en la conformidad entre el enunciado bíblico y su realización. Ahí está la gran diferencia entre la verdad lógica griega y la verdad existencial israelita»: José Manuel SÁNCHEZ CARO, Introducción a la Sagrada Escritura, o. c..., 219.

11 Fabrice Hadjadj, La fe de los demonios (o el ateísmo superado) (Granada, Nuevo Inicio, 2011) 95. 
a través del fatigoso camino de una relación entre Él y su pueblo implica que la verdad bíblica también deba ser entendida de manera dialógica y progresiva, una búsqueda en la que Dios involucra a su criatura libre e inteligente en pos de la verdad. Así afirmaba Joseph Ratzinger en unas conferencias cuaresmales que predicó en Múnich en 1981 y que entregó a la imprenta en 1985: «La Biblia es, pues, expresión del empeño de Dios por hacerse progresivamente comprensible al hombre; pero es al mismo tiempo expresión del esfuerzo humano por comprender progresivamente a Dios» ${ }^{12}$.

En tercer lugar, pensar la verdad de la Escritura desde el prisma de la encarnación implica considerar que Dios reconoce al ser humano, en su creaturalidad, como capax Dei. Puesto que lo ha creado a su imagen, la criatura humana, y su lenguaje, puede ser vehículo adecuado -si bien, como la analogía, siempre deficiente e incompleto- para comunicar sus misterios divinos ${ }^{13}$. Esta convicción llena de esperanza al ser humano que descubre que el diálogo entre el cielo y la tierra, gracias a la encarnación, es posible.

Y, en cuarto lugar, si Dios ha querido revelar su Palabra divina por medio de palabras humanas es para confrontar al creyente con sus hermanos. Para evitar la ilusión fundamentalista del que se cree en posesión de la verdad absoluta, el Dios de Jesucristo invita a discernir su Palabra en las entretelas de las palabras de unos hombres semejantes al lector. Ello implica que no se pueda llegar a Dios sin pasar por el hermano. Juan lo afirmó categóricamente: «Quien no ama a su hermano, a quien ve, no puede amar a Dios, a quien no ve» (1 Juan 4,20). La relación de alianza no solo tiene una dimensión vertical, también emplaza a la relación horizontal. ¿Por qué leer, entonces, la Biblia? Porque nos lega las experiencias privilegiadas y determinantes de unos hombres en las que Dios ha querido comunicar su revelación.

Podríamos dar otras razones de por qué es preferible este discreto estilo divino, como decía Benedicto XVI, pero prefiero concluir esta consideración con un texto de Blaise Pascal que ilustra inmejorablemente las ideas balbucientes que intento transmitir:

El hombre no se sentiría corrompido si no viviera en la oscuridad; y no esperaría el remedio si la luz no existiera. Por eso para nosotros es justo, además de útil, que Dios en parte se oculte y en parte se descubra, ya que es igualmente peligroso para él conocer a Dios sin conocer su miseria o conocer su propia miseria sin conocer a Dios ${ }^{14}$.

12 Joseph Ratzinger, Creación y pecado (Pamplona, Eunsa, 1992) 31.

13 Cf. René Latourelle, Teología de la revelación, o. c...,461: «Cristo pudo utilizar todos los recursos del universo creado para darnos a conocer a Dios y su vida divina, porque la palabra creadora precedió y da fundamento a la palabra reveladora, y porque una y otra tienen por principio a la misma palabra interior de Dios. La revelación de Cristo supone la verdad de la analogía».

14 Blaise PASCAL, Pensamientos. Edición de Mario Parajón (Madrid, Cátedra, 1998) § 446, pág. 182. 
En fin, este epígrafe sobre la importancia de aceptar el principio de la encarnación para entender la verdad paradójica de la Sagrada Escritura no puede terminar sin expresar, al menos de pasada, que la encarnación se produjo por la acción graciosa del Espíritu Santo. Es la inspiración divina la que hace de estos escritos humanos una Palabra divina de salvación. En conclusión, el descenso a la semioscuridad de nuestra carne es quizás uno de los misterios más pavoroso de un Dios que, por medio de la acción de su Espíritu, ha enviado a su Hijo a nacer de mujer (cf. Gál 4,4) y ha hablado por medio de hombres como nosotros (cf. 2 Pedro 1,21).

\section{VERDAD Y SALVACIÓN}

Acabo estas consideraciones sobre el enigma teológico de la verdad bíblicas aliendo al paso de un error común entre los creyentes. El creyente al que me refiero ha superado el escándalo que le produce aceptar que algunas afirmaciones bíblicas posean imperfecciones en cuestiones naturales o históricas; y también ha llegado a acoger como una gracia inesperada que Dios haya elegido este estilo paradójico de revelarse; pero, a la hora de la práctica, tiende a leer la Biblia discriminando, por un lado, los textos que le parecen más sugerentes de otros que le resultan más extraños y, por otro lado, pretende decantar la paja de lo contingente (cuestiones literarias, problemas históricos, etc.) del grano de lo perdurable (las verdades reveladas que le tocan el corazón).

Estas dos tendencias, sin embargo, son rechazadas por el magisterio eclesial. Por un lado, escoger un canon dentro del canon - preferir unos textos sobre otros- fue el error de Lutero y, en el fondo, es una desviación que nos conduce a privilegiar el espíritu sobre la carne o, si quieren, a escoger aquello que nos parece más atrayente, postergando lo más exigente, esforzado o confuso. De nuevo, como decía Tertuliano, «la carne es el quicio de nuestra salvación» ${ }^{15}$. En los textos confusos o difíciles también habla Dios. Por ello nos deberíamos empeñar por no discriminar y ponernos a la escucha también allá donde nos parece que nada podremos (o queremos) oír.

Por otro lado, es muy frecuente querer separar el contenido de su forma de expresión, el mensaje de su ropaje literario o histórico, del que pensamos ilusoriamente que nos podemos desembarazar sin dificultad. Por explicarlo de forma gráfica, imaginamos la Sagrada Escritura como una naranja que, tras ser exprimida con el instrumental adecuado (la exégesis), puede dar un zumo sabroso (el mensaje teológico), desechando la cáscara inservible (cuestiones lingüísticas, históricas, contextuales). Sin embargo, la cáscara importa tanto como el zumo: solo entiende a Isaías, a Mateo o a Pablo el que comprende la dinámica y retórica de sus oráculos, relatos o argumentaciones; más aún, estas

15 De resurrectione carnis, 8.3 (PL 2.806). 
mismas dinámicas poéticas, narrativas y argumentativas son ya el mensaje en acto. ¡La forma es ya evangelio!

De hecho, el papa León XIII en la Providentissimus Deus (1893) declaró como ilícitos los intentos de August Rohling, entre otros (Newman, Didiot, D'Hulst, etc.), quien propuso la teoría de la diferenciación de la verdad bíblica: solo sería verdad lo que atañe al dogma y a la moral, lo demás podría ser erróneo. Así dice el documento pontificio: «Ni debe tampoco tolerarse el procedimiento de aquellos que, para salir de estas dificultades, no vacilan en sentar que la inspiración divina toca a las materias de fe y costumbres y nada más» ${ }^{16}$. Alguno pensaría que la solución era buena...

Por tanto, según el magisterio de la Iglesia, todo el texto bíblico es verdad, y no solo aquellas afirmaciones sobre fe y moral. Así afirmó solemnemente el Concilio: «Pues, como todo lo que los autores inspirados o hagiógrafos afirman, debe tenerse como afirmado por el Espíritu Santo, hay que confesar que los libros de la Escritura enseñan firmemente, con fidelidad y sin error, la verdad que Dios quiso consignar en las sagradas letras para nuestra salvación» (Dei Verbum 11). Precisamente este párrafo nos da la clave final para entender en qué sentido es verdad la Escritura. La Iglesia afirma que todo el texto es verdad, pero no en todos los sentidos. La Biblia no es un libro de historia, de cosmología, de botánica y, ni siquiera, de moral. Eso no elimina o fragmenta su verdad, pero sí la cualifica. Como dice el Concilio, la Sagrada Escritura es toda ella «verdad salvadora» (Dei Verbum 7), «para la salvación del hombre» (Dei Verbum 2), «para salvación nuestra» (Dei Verbum 11). De hecho, el mismo León xiII reconocía ya a finales del siglo XIX que el Espíritu Santo hablaba a través de escritores sagrados que no buscaban enseñar a los hombres la naturaleza de las cosas, porque esto no les servía para su salvación ${ }^{17}$. Muchas figuras eminentes de la tradición eclesial habían afirmado así que la verdad bíblica es de índole salvífica: «El Señor quería hacer cristianos y no astrólogos» ${ }^{18}$; y «la Sagrada Escritura describe todo el universo en cuanto conviene conocerlo para la salvación» ${ }^{19}$.

En conclusión, todo enunciado de la Escritura, incluso el que carece de comprobación científica o histórica, conserva el tenor de «verdad» en cuanto que tiene una significación profunda en el orden de la salvación y desvela el

16 LeÓn XIII, Providentisimus Deus (Denzinger - Hünerman § 3291). Cf. August RoHLING, «Die Inspiration der Bibel und ihre Bedeutung für die freiere Forschung», Natur und Offenbarung 18 (1872) 97-108, 385-394. Cf. el resumen deestas teorías en Valerio MANucci, Introducción general a la Sagrada Escritura (Bilbao, Desclée de Brouwer, $\left.{ }^{4} 1995\right)$ 228-231.

17 Cf. LeÓn XIII, Providentisimus Deus (Denzinger - Hünerman § 3288), quien cita, a su vez, a San Agustín, De Genesi ad litteram 2.9.20 (PL 34.270-271; BAC Obras Completas XV, pag. 642).

18 San Agustín, De Actis cum Felice Manichaeo 1.10 (PL 42.525; BAC Obras Completas XXX, pag. 481).

19 San Buenaventura. Breviloquio. Prólogo 3 (BAC Obras Completas I, pag. 169). Así también, afirma Santo TomÁs DE Aquino: «En cambio todo aquello que no dice relación con la salvación es ajeno a la materia de la profecía» (Cuestión sobre la profecía, q.12 a.2; BAC Obras Completas. Opúsculos y cuestiones selectas V, pag. 819). El tema de la relación entre verdad bíblica y salvación ha sido tratado por la Pontificia Comisión Bíblica, Inspiración y verdad, o. c..., §§ 63-103. 
misterio de Dios. En la Escritura, en su conjunto y en cada uno de sus escritos, se va esclareciendo la verdad de una historia de amor que relata cómo Dios ha querido salvar a los hombres, y cómo ha ido cumpliendo sus promesas en el misterio pascual de Cristo. La lectura de los textos «con el mismo Espíritu con el que fueron escritos» (Dei Verbum 12) es el camino adecuado para adentrarse en dicho drama de salvación.

Esto nos lleva a concluir que la pregunta por la verdad de la Biblia, en última instancia, se transforma en un interrogante sobre nuestra propia verdad. ¿Qué es lo que estamos buscando: seguridad, vanidad, verdad? El cuarto evangelio presente a Jesús como el Logos, la Palabra divina hecha carne (Jn 1,14). El lector espera sus primeras palabras en el relato con gran expectación. Ellas, dichas a los primeros discípulos, deben ser nuestra premisa de lectura: «Jesús se volvió y, al ver que lo seguían, les pregunta:"¿Qué buscáis?"» (Jn 1,38). Como apuntamos anteriormente, el enigma de la verdad bíblica no radica en el ámbito de la lógica filosófica, sino en la pregunta por la fidelidad de una relación. Así pues, ¿qué buscamos? Ojalá que nuestra búsqueda, a la hora de leer el texto bíblico, esté a la altura de aquello que se nos ofrece: nada menos que la amistad divina y la salvación en Cristo, «el camino, la verdad y la vida» (Jn 14,6). 